\title{
Dental Treatment during Covid-19: An Orthodontic Perspective
}

\author{
Sunegha Kundal ${ }^{*}$, Tulika Shokeen ${ }^{2}$, Anubhav Bansal ${ }^{3}$ \\ ${ }^{I}$ Orthodontist, Private Practitioner, Jammu, Jammu \& Kashmir, India \\ ${ }^{2}$ Orthodontist, Private Practitioner, Delhi, India \\ ${ }^{3}$ Orthodontist, Private Practitioner, Delhi, India
}

\begin{abstract}
*Corresponding Author: Dr. Sunegha Kundal, Orthodontist, Private Practitioner, Jammu, Jammu \& Kashmir, India. Email: suneghakundal@gmail.com
\end{abstract}

\begin{abstract}
The ongoing COVID-19 pandemic poses a unique challenge for oral health-care providers. With patients' oropharyngeal region being their working ground, treating patients without increasing risk of transmitting the infection becomes a precarious task. There has been an onslaught of literature on the subject, leaving the clinician overwhelmed and unsure of the most effective measures. This review aims to equip an orthodontic practitioner with current understanding of severe acute respiratory syndrome coronavirus 2 (SARS-CoV2), its transmission modes and risks, and the infection control measures required to safely and confidently deliver orthodontic care to the patients. In this time of crisis, it becomes practising clinicians' moral obligation to not contribute to the increasing spread of this highly infectious disease and minimize the risk of infection to their patients, themselves, as well as their team members.
\end{abstract}

Keywords: Covid-19, Coronavirus, Orthodontics, Dentistry, Aerosol

\section{INTRODUCTION}

\subsection{Covid-19: The Beginning of the Pandemic}

Corona viruses, the now 'infamous' virus family, affects humans and animals alike.[1] When an outbreak of severe Pneumonia emerged in December of 2019 in Wuhan (China), little could be speculated about its etiology or the massive impact it was to have world over. Bats presented as possible hosts while the infection itself was believed to be transmitted to humans through intermediate hosts. In early 2020, World Health Organization (WHO) identified the pathogen causing the infections to have a genomic buildup similar to corona viruses related to SARS (Severe Acute Respiratory Syndrome) and MERS (Middle- East Respiratory Syndrome), thus naming it novel coronavirus 2019nCoV.[2] It was later modified to SARS-Cov-2 (Severe Acute Respiratory Syndrome coronavirus 2), with the disease it caused named as COVID-19.[3]
On 11th March 2020, COVID-19 attained a pandemic status when it had spread to almost 1,26,140 people across 114 countries.[4] Until 27 th July 2020, the total number of cases worldwide are around $16 \mathrm{M}$, with India alarmingly at the third pedestal among countries with highest number of cases.[5] Till date, India has reported 14,36,025 cases in total with 9,18,737 recovered and 32812 deaths.[6] Fever (83\%-98\%), dry cough (76\%-82\%) and fatigue $(11 \%-44 \%)$ are the most common symptoms of COVID-19.[7] Whereas, other symptoms like body aches, headache, sore throat, nasal congestion, conjunctivitis, loss of taste or smell, discoloration of fingers or toes, skin rashes are seen less frequently. Patients with severe illness experience shortness of breath, chest pain or pressure, and loss of speech or movement. [1]

\subsection{Threat to Health Workers and Dental Fraternity}

Health Care Workers (HCWs) at the front-line of COVID-19 emergency response engender a 
high risk of infection and cross-contamination. By 3rd June 2020, an estimated 2,30,000 HCWs had contracted the virus globally, with over 3000 casualties. [8,9] On16th July 2020, the severity of the situation led Indian Medical Association (IMA) to issue a Red Alert for the safety of medicos and medical staff involved in COVID-19 duties. [10]

The dental profession also fell under the highest risk category, creating a hurdle in smooth functioning of clinical dental practices.[11-14] This is hardly surprising as most dental procedures expose the operator to patient's droplets and aerosols at extremely close quarters. A revision in the operating protocols to ensure safety of patients, staff, and the clinician became need of the hour owing to the highly transmissible potential of SARS-CoV-2. Orthodontists themselves attend multiple patients a day, many of them being children. Thus, adopting strict infection control measures is indispensable to the orthodontic practice amidst the ongoing pandemic. This review outlines such measures that need to be adopted during an orthodontic visit to minimize transmission through contact as well as through Orthodontic Procedures.

\subsection{Pathways of Transmission $[15,16]$}

Bearing similarities to other respiratory infections in general, COVID-19 infection is reportedly spread via respiratory droplets (during coughing, sneezing, breathing and talking) and contact routes (direct or indirect). [17-22] SARS CoV-2 has been shown to be present in both saliva and faeces of the affected patients.[23] The average size of SARS-Cov-2 is $0.125 \mu \mathrm{m}$, with an incubation period of 5-6 days, that may range from 2-14 days. [24,25] During airborne transmission via droplet nuclei $(<5 \mu \mathrm{m})$, the particles remain suspended in the air for long durations and can disseminate to a distance of over 1 meter, getting trapped in the respiratory tract. Evidently, airborne transmission of SARS-Cov-2 is possible during aerosol generating procedures, with the virus found to be persisting in air for an average of 3 hours post such a procedure. [26] Moreover, ACE-2 (Angiotensin Converting Enzyme 2) receptors which act as portal of entry for SARSCoV-2 into cells are extensively found in the oronasal mucosa and nasopharynx, inadvertently increasing the vulnerability of dental professionals to the virus. [27]

\subsection{Transmission Risks in Orthodontic Practice [28]}

Possible routes of transmission of SARS-CoV-2 in orthodontists can be enumerated as follows:

1. Saliva: The presence of enormous amounts of ACE-2 receptors has been reported on the human tongue and oral mucosa, greatly increasing the possibility of SARS-Cov-2 transmission to the clinician while treating an affected patient. [29-31]

2. Respiratory droplets: Generated during coughing, sneezing, or the clinical procedure. [22]

3. Aerosols: Bonding, bracket repositioning, and debonding are likely to generate aerosols. The contamination potential of these aerosols depends on the viral load, as well as on the quantity of saliva, nasal and throat secretions, blood, periodontal, or presence of other dental infections. Microorganisms can also adhere to the surface of dental unit waterlines whose narrow design and failure of anti-retraction valve can further spread the infection when they are used during a procedure.[32,33] The aerosols are majorly generated by scalers (sonic and ultrasonic), air water syringe, and the rotary headpiece. [34,35] They can spread to a distance of over $2 \mathrm{ft}$ from the dental chair, with traces found not only in the nose of operating doctor but the assistant as well, penetrating their protective facial gears. [36] Presence of aerosols on operators' scrub has also been documented.[37]

4. Indirect contact: Coming in contact with infected surfaces, via aerosol transmission in a confined space, or through contaminated 
surfaces.[38,39] Transmission can also occur through salivary contact while removing/delivering removable appliances, aligners, rubber bands, or molar bands.

5. Orthodontic instruments and materials: Studies reveal that reusing wires, bands, brackets, debonding burs, miniscrews, intraoral markers, photographic mirror, and retractors in the orthodontic practice, without appropriate sterilization and disinfection, can be a principal source of contamination.[40-44] Using orthodontic instruments and materials without implementing strict sterilization protocols can severely compromise infection control measures in an orthodontic office.

\subsection{Precautions}

\subsubsection{Precautions for the general population} [18]

1. Wash and clean your hands regularly and thoroughly using alcohol based hand rub or with soap and water.

2. Maintain a distance of at least 1 meter (3 feet) from others to avoid inhaling the droplets.

3. Stay away from crowded place as they impose a higher risk of contamination.

4. Abstain from touching your mouth, eyes or nose with hands as it increases the risk of transferring the virus to face, and thereafter into the body.

5. Cover your mouth and nose with elbow or tissue when coughing or sneezing.

6. Even minor symptoms like cough, headache, mild fever are an indication for self-isolation.

7. Proper medical attention is advised in case of high fever, cough and shortness of breath.

1.5.2. Precautions in an Orthodontic Office [2, 16]
1. Teledentistry: Use smartphones, webcams, and video conferencing applications to provide emergency aid, initial consultation, and expert opinion to the patients.[45]

2. Screening and evaluation: The guidelines recommend postponing all routine dental procedures and considering emergency treatments only.[46,47] It is mandatory to screen the patients for any COVID-19 symptoms, record body temperature, take medical and travel history, history of contact with a confirmed COVID-19 case in the past 14 days. Re-schedule the appointment and refer the patient to a dedicated COVID-19 facility in case of any suspicion.[48]

3. Appointments: The appointments should be managed such that the waiting area is not crowded at any time of the day. Patients should be instructed to visit the dental office alone, whenever possible. Aerosol generating procedures should be deferred unless urgent and such an appointment should invariably be shifted towards the end of the day.[49]

4. Hygiene protocols: Following stringent hygiene protocols is the need of the hour. Washing hands with soap and water, rubbing for 20 seconds is known to disintegrate the outer fat layer of SARS-CoV-2 while the remaining protein structure dissolves on its own. [50] It is mandatory for the staff and the patients to frequently sanitize their hands (soap \& water or alcohol base sanitizer) when entering the dental office, on entry into the operatory and upon dismissal post the procedure.[51] Patients should be asked to rinse their mouth before the procedure and provided with a 0.12-0.2 \% chlorhexidine gluconate, $1 \%$ hydrogen peroxide or $0.2 \%$ povidine iodine solution to reduce the microbial load of the oral cavity. $[52,53]$

5. Personal Protective Equipment (PPE): [54] Any contact with ocular, nasal and mouth mucosa is to be avoided. [55] It is essential for the clinician to wear the PPE which comprises 
of impermeable gown, facial mask, gloves, face shield, head cap, and eye protection glasses; all before entering the operatory. [47,56] The sequence for proper wear and removal of the PPE is as follows: when wearing- start by washing the hands, followed by wearing the gown, then the masks/respirators, protective eyewear/shield, and finally the gloves. When removing, take off the gloves first, wash hands thoroughly, remove the eyewear/shield, followed by the gown; masks/respirators are the last to be taken off. [54]

6. Training the staff: Before commencing regular clinical operations during the pandemic, a comprehensive training of the staff should be arranged, wherein they are made aware of the symptoms, possible routes of transmission, and measures to control the contamination and infection spread. It is advisable to stay informed and update the information concerning the SARS-CoV-2 infection regularly through approved sources only. [47]

7. Operatory: Dental office should be well ventilated and equipped with efficient airfiltration system like HEPA (high efficiency particulate air) filters, activated carbon and UV chambers. Activated carbon and HEPA filters are said to filter almost $100 \%$ particulate matter, including particles of size 0.001 and $0.1 \mu \mathrm{m}$. [57] The use of high-volume evacuation suction, capable of removing $100 \mathrm{ft} 3$ of air per minute to remove droplets and minimize aerosolization, is recommended by ADA. [58] The risk of infection can also be reduced by flushing the waterline for at least 2 mins or using disinfectant. [59]

\section{Orthodontic instruments and materials:} Dental instruments have been categorized into Critical, Semi-critical and Non-critical depending upon their potential risk of crosscontamination, with critical carrying the highest and non- critical the lowest cross-contamination risk.[60] Orthodontic instruments are considered Semi-critical as they do not penetrate the soft tissues or contact blood, and only come in contact with the mucous membrane and nonintact skin.[61] The recommended sterilization procedure for orthodontic instruments includes optimal cleaning and rinsing followed by thermo-disinfection, and finally sterilizing using cassettes or containers with holes in a steam autoclave. Use of single patients packed orthodontic materials (archwires, brackets, bands, buttons, ligatures) is recommended owing to their negligible risks of air and hand contamination. Furthermore, spool dispensers for elastomeric chains and single patient assembly of ligatures aided with cold sterilization $(0.12 \%$ Chlorehexidine solution for 10 minutes and $0.2 \%$ peracetic acid solution for 30 mins)[62] are known to reduce contamination.[60] Orthodontic markers, photographic mirrors, retractors, carbide burs, and miniscrews should be thoroughly disinfected and decontaminated before reuse.[2]

9. Handling the waste: The onslaught of corona virus cases has lead us to strictly follow and review our clinical waste management protocols as per the issued guidelines. We should aim at reducing or minimizing the transmission of infection. The waste should be separated based on the categories and disposed off in the dedicated and properly labelled containers.[63] Further information about the medical waste management is recommended.

\subsection{Guidelines Issued for the Dental Practices}

Distinct guidelines have been issued by the authorities like WHO, Health Ministries, Medical and Dental Associations, to perpetuate safe environments at healthcare and dental facilities. With the constantly evolving discoveries about SARS-CoV-2, these recommendations/guidelines need to be reviewed regularly. Figure 1 depicts the flow chart for the management of emergency orthodontic problems.[64,65] 


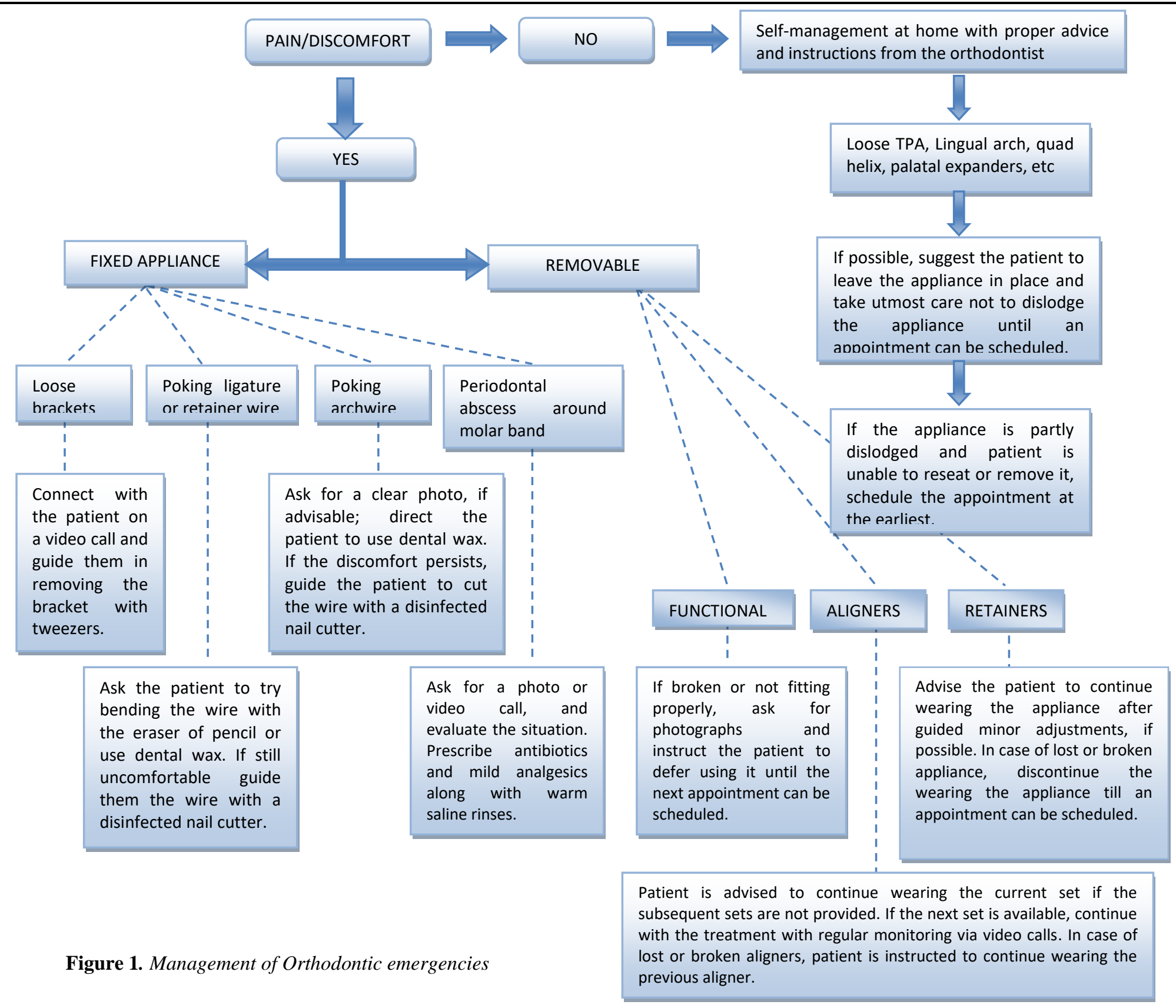




\section{CONCLUSION}

Despite the governmental restrictions and measures being taken, COVID-19 appears to be a long-drawn battle that we continue to fight. The pandemic makes it imperative to formulate a contingency plan and adopt stringent infection control measures in our practices. This review provided a succinct overview of the situation and outlined a few practical measures that can be easily adopted. While treatment advice should be first delivered remotely whenever possible, prioritizing patients' appointments, effective communication and triage, and transmission-based precautions can enable us to successfully continue in-person appointments and serve the patients. Prevention protocols for the spread of COVID-19 are likely to undergo changes as research into the same continues, therefore, it is advised to regularly update yourself with recommendations from the national official committees as per the local epidemic situation.

\section{REFERENCES}

[1] Q\&A on coronavirus (COVID-19). Available at: https://www.who.int/emergencies/diseases/ novel-coronavirus-2019/question-and-answershub/q-a-detail/q-a-coronaviruses [Last accessed on 2 Aug, 2020]

[2] Turkistani KA. Precautions and recommendations for orthodontic settings during the COVID-19 outbreak: A review. American Journal of Orthodontics and Dentofacial Orthopedics. 2020;158(2):175-81.

[3] Gorbalenya AE, Baker SC, Baric RS, de Groot RJ, Drosten C, Gulyaeva AA, et al. The species Severe acute respiratory syndrome-related coronavirus: classifying 2019-nCoV and naming it SARS-CoV-2. Nat Microbiol. 2020;5(4):536-44.

[4] WHO declares Covid-19 outbreak a pandemic. Available at: https://www.pharmaceuticaltechnology.com/news/who-declares-covid-19pandemic/ [Last accessed on 2 Aug, 2020]

[5] Google News. Available at: https://news.google.com/covid19/map?hl=en$\mathrm{IN} \& \mathrm{gl}=\mathrm{IN} \&$ ceid=IN\%3Aen [Last accessed on 21 Aug, 2020]

[6] Covid19INDIA. Available at: https://www.covid19india.org/ [Last accessed on 21 Aug 2020]
[7] Covid-19- New Insights on a Rapidly Changing Epidemic. Available at: https://jamanetwork.com/journals/jama/fullartic le/2762510 [Last accessed on 4 Aug, 2020]

[8] Over 239,000 healthcare workers infected with virus: Study. Available at: https://www.aa.com.tr/en/europe/over-230-000health-workers-infected-with-virusstudy/1863982\#_[Last accessed on 4 Aug, 2020]

[9] More than 1000 Doctors infected with Covid19 in India; Global Tally Nearly 3,000. Available at: https://weather.com/enIN/india/coronavirus/news/2020-07-18-morethan-1000-doctors-infected-with-covid-19-inindia [Last accessed on 4 Aug, 2020]

[10] IMA says 99 doctors succumbed to COVID-19, issues 'Red alert' for medicos. Available at: https://health.economictimes.indiatimes.com/ne ws/industry/ima-says-99-doctors-succumbedto-covid-19-issues-red-alert-formedicos/76989998 [Last accessed on 5 Aug, 2020]

[11] Dentists rank highest for infection risk but have no increased Covid-19 death rate. Avilable at: https://www.dentistry.co.uk/2020/06/24/dentist s-highest-infection-no-death/ [Last accessed on 5 Aug, 2020]

[12] Workers who face the greatest coronavirus risk. Available at: https://www.nytimes.com/ interactive/2020/03/15/business/economy/coron avirus-worker-risk.html [Last accessed on 5 Aug, 2020]

[13] SARS-CoV-2: Dentistry tops list of most dangerous jobs. Available at: https://coronavirus.dental-tribune.com/news/ sars-cov-2-dentistry-tops-list-of-mostdangerous-jobs/ [Last accessed on 5 Aug, 2020]

[14] UPDATED: Timeline of the Coronavirus. Available at: https://www.thinkglobalhealth.org/article/updat ed-timeline-coronavirus [Last accessed on: 5 Aug,2020]

[15] Modes of transmission of virus causing COVID-19: implications for IPC precaution recommendations. Available at https://www.who.int/news-room/commentaries/ detail/modes-of-transmission-of-virus-causingcovid-19-implications-for-ipc-precautionrecommendations [Last accessed on 5 Aug,2020]

[16] Mostoufi B, Ashkenazie Z, Abdi J, Chen E, De Paola LG. COVID-19 and the dental profession: Establishing a safe dental practice for the coronavirus era. J Global Oral Health. 2020;3(1):41-8. 
[17] Liu J, Liao X, Qian S et al. Community transmission of severe acute respiratory syndrome coronavirus 2, Shenzhen, China, 2020. Emerg Infect Dis. 2020; 26(6):1320-23.

[18] Chan J, Yuan S, Kok K et al. A familial cluster of pneumonia associated with the 2019 novel coronavirus indicating person-to-person transmission: a study of a family cluster. The Lancet. 2020;395(10223):514-23.

[19] Li Q, Guan X, Wu P, et al. Early transmission dynamics in Wuhan, China, of novel coronavirus-infected pneumonia. $N$ Engl J Med. 2020;382(13):1199-1207.

[20] Huang C, Wang Y, Li X, et al. Clinical features of patients infected with 2019 novel coronavirus in Wuhan, China. The Lancet. 2020;395(10223):497-506.

[21] Burke RM, Midgley CM, Dratch A, Fenstersheib M, Haupt T, Holshue M,et al. Active monitoring of persons exposed to patients with confirmed COVID-19 - United States, January-February 2020. MMWR Morb Mortal Wkly Rep. 2020;69(9):245-246.

[22] Coronavirus COVID-19 (SARS-CoV-2). Johns Hopkins ABX Guide. United States: The Johns Hopkins University; 2020. Available at: https://www.hopkinsguides.com/hopkins/view/ Johns_Hopkins_ABX_Guide/540747/all/Coron avirus_COVID_19_SARS_CoV_2_ [Last accessed on: 8 Aug 2020]

[23] To KK, Tsang OT, Yip CC, Chan KH, Wu TC, Chan JM et al. Consistent Detection of 2019 Novel Coronavirus in Saliva. Clin Infect Dis. 2020 Jul 28;71(15):841-843.

[24] Fehr AR, Perlman S. Coronaviruses: An overview of their replication and pathogenesis. Methods Mol Biol. 2015;1282:1-23.

[25] CDC-Interim Clinical Guidance for Management of Patients with Confirmed Coronavirus Disease (COVID-19). Available at: https://www.cdc.gov/coronavirus/2019$\mathrm{ncov} / \mathrm{hcp} / \quad$ clinical-guidance-managementpatients.html. [Last accessed on 8 Aug 2020].

[26] Van Doremalen N, Bushmaker T, Morris DH, Holbrook MG, Gamble A, Williamson BN, Tamin A, Harcourt JL, Thornburg NJ, Gerber SI, Lloyd-Smith JO. Aerosol and surface stability of SARS-CoV-2 as compared with SARS-CoV-1. New England Journal of Medicine. 2020 Apr 16;382(16):1564-7.

[27] Hamming I, Timens W, Bulthuis ML, Lely AT, Navis GJ, van Goor H. Tissue distribution of ACE2 protein, the functional receptor for SARS coronavirus. A first step in understanding SARS pathogenesis. J Pathol. 2004;203(2):631-7.
[28] Suri S, Vandersluis YR, Kochhar AS, Bhasin $\mathrm{R}$, Abdallah MN. Clinical orthodontic management during the COVID-19 pandemic. The Angle Orthodontist. 2020; 90(4): 473-484.

[29] Sabino-Silva R, Jardim ACG, Siqueira WL. Coronavirus COVID-19 impacts to dentistry and potential salivary diagnosis. Clin Oral Investig. 2020;24(4):1619-21.

[30] Gu J, Han B, Wang J. COVID-19: gastrointestinal manifestations and potential fecal-oral transmission. Gastroenterology. 2020;158(6):1518-9.

[31] Xu H, Zhong L, Deng J, Peng J, Dan H, Zeng $X$, et al. High expression of ACE2 receptor of 2019-nCoV on the epithelial cells of oral mucosa. Int J Oral Sci. 2020;12:8.

[32] O“Donnell MJ, Boyle MA, Russell RJ, Coleman DC. Management of dental unit waterline biofilms in the 21 st century. Future Microbiol. 2011; 6(10): 1209-26.

[33] Spagnolo AM, Sartini M, Cave DD, Casini B, Tuvo B, Cristina ML. Evaluation of microbiological and free-living protozoa contamination in dental unit waterlines. Int $J$ Environ Res Public Health. 2019;16(15)E2648.

[34] Jain M, Mathur A, Mathur A, Mukhi PU, Ahire M, Pingal C. Qualitative and quantitative analysis of bacterial aerosols in dental clinical settings: Risk exposure towards dentist, auxiliary staff, and patients. $J$ Family Med Prim Care. 2020; 9(2): 1003-8.

[35] Veena HR, Mahantesha S, Joseph PA, Patil SR, Patil SH. Dissemination of aerosol and splatter during ultrasonic scaling: a pilot study. J Infect Public Health. 2015; 8(3): 260-5.

[36] Bentley CD, Burkhart NW, Crawford JJ. Evaluating spatter and aerosol contamination during dental procedures. $J$ Am Dent Assoc. $1994 ; 125: 579-84$.

[37] Huntley DE, Campbell J. Bacterial contamination of scrub jackets during dental hygiene procedures. J Dent Hyg. 1998;72:1923.

[38] Rodriguez-Morales AJ, MacGregor K, Kanagarajah S, Patel D, Schlagenhauf P. Going global-travel and the 2019 novel coronavirus. Travel Med Infect Dis. 2020;33:101578.

[39] Wax RS, Christian MD. Practical recommendations for critical care and anesthesiology teams caring for novel coronavirus (2019-nCoV) patients. Can J Anaesth. 2020;67:568-76.

[40] Irfan S, Irfan S, Fida M, Ahmad I. Contamination assessment of orthodontic bands 
after different pre-cleaning methods at a tertiary care hospital. J Orthod. 2019;46:220-4.

[41] Pithon MM, Ferraz CS, Rosa FCS, Rosa LP. Sterilizing elastomeric chains without losing mechanical properties. Is it possible? Dental Press J Orthod. 2015;20:96-100.

[42] Omidkhoda M, Rashed R, Bagheri Z, Ghazvini $\mathrm{K}$, Shafaee H. Comparison of three different sterilization and disinfection methods on orthodontic markers. J Orthod Sci. 2016;5:147.

[43] Coley-Smith A, Rock WP. Bracket recyclingwho does what? Br J Orthod. 1997;24:172-4.

[44] Machen DE. Orthodontic bracket recycling. Am J Orthod Dentofacial Orthop. 1993;104:618-9.

[45] Tele-dentistry serves as a lifeline for oral health patients during Covid-19: Amrinder Singh. Available at: https://health.economictimes.indiatimes.com/ne ws/industry/tele-dentistry-serves-as-a-lifelinefor-oral-health-patients-during-covid-19amarinder-singh/75373762. [Last accessed on 15 Aug 2020]

[46] Guo H, Zhou Y, Liu X, Tan J. The impact of the COVID-19 epidemic on the utilization of emergency dental services. $J$ of Dental Sciences. 2020.

[47] Meng L, Hua F, Bian Z. Coronavirus disease 2019 (COVID-19): emerging and future challenges for dental and oral medicine. J Dent Res. 2020;99:481-7.

[48] Peng X, Xu X, Li Y, Cheng L, Zhou X, Ren B. Transmission routes of 2019-nCoV and controls in dental practice. Int J Oral Sci. 2020;12:9.

[49] Gan WH, Lim JW, Koh D. Preventing intrahospital infection and transmission of COVID19 in healthcare workers. Saf Health Work. 2020;2:241-43.

[50] WHO Guidelines on Hand Hygiene in Health Care: First Global Patient Safety Challenge Clean Care Is Safer Care. World Health Organization. 2009;11.

[51] Summary of Infection Prevention Practices in Dental Settings. Centers for Disease Control and Prevention. Available from: https://www.cdc.gov/oralhealth/infectioncontro 1/summary-infection-preventionpractices/standard-precautions.html [Last accessed on 2020 Apr 25].

[52] Marui VC, Souto MLS, Rovai ES, Romito GA, Chambrone L, Pannuti CM. Efficacy of preprocedural mouthrinses in the reduction of microorganisms in aerosol: a systematic review. J Am Dent Assoc. 2019;150(12):101526.

[53] Fine DH, Mendieta C, Barnett ML, Furgang D, Meyers R, Olshan A, et al. Efficacy of preprocedural rinsing with an antiseptic in reducing viable bacteria in dental aerosols. $J$ Periodontol. 1992;63:821-4.

[54] Selection and Use of PPE. Available at: https://www.dentistryiq.com/practicemanageme $\mathrm{nt} /$ staffing/article/ 16348246/selection-and-useof-ppe. [Last accessed on 17 Aug 2020]

[55] Lu CW, Liu XF, Jia ZF. 2019-nCoV transmission through the ocular surface must not be ignored. Lancet. 2020;395: e39

[56] Zhang W, Jiang X. Measures and suggestions for the prevention and control of the novel coronavirus in dental institutions. Front Oral Maxillofac Med. 2020;2:4.

[57] Perry JL, Agui JH, Vijayakumar R. Submicron and Nanoparticulate Matter Removal by Heparated Media Filters 15 and Packed Beds of Granular Materials. United States. NASA;2016. Available at: https://ntrs.nasa.gov/archive/nasa/ casi.ntrs.nasa.gov/20170005166.pdf.[Last accessed on 18 Aug 2020]

[58] Summary of ADA Guidance During the COVID-19 Crisis; 2020. Available at: http://success.ada.org/ /media/CPS/Files/COVI D/OSHA_Guidance_Summary_Dentistry_Wor kers_And_Employers.pdf [Last accessed on 18 Aug 2020]

[59] Chate RA. An audit improves the quality of water within the dental unit water lines of general dental practices across the East of England. Br Dent J. 2010;209:E11.

[60] Centers for Disease Control and Prevention. Guidelines for Infection Control in Dental Health-Care Settings - 2003. MMWR 2003;52(No. RR-17)[20].

[61] Barenghi L, Di Blasio A. Orthodontic instruments and supplies: Are they semicritical or critical items? American journal of infection control. 2017;45(2):210-1.

[62] Losito KAB, Lucato AS, Tubel CAM, Correa CA, dos Santos JCB. Force decay in orthodontic elastomeric chains after immersion in disinfection solutions. Braz J Oral Sci. 2014;13:266-9.

[63] Water, sanitation, hygiene, and waste management for SARS-CoV-2, the virus that causes COVID-19. Available at: https://www.who.int/publications/i/item/WHO2019-nCoV-IPC-WASH-2020.4. [Last accessed on 20 Aug, 2020]. 
[64] Caprioglio, A., Pizzetti, G.B., Zecca, P.A., Fastuca R., Maino G, Nanda R. Management of orthodontic emergencies during 2019NCOV. Prog Orthod. 2020;21(10):1-4.
[65] Recommendations for Orthodontics during COVID-19 pandemic. Available at: https://www.rcseng.ac.uk/-/media/files/rcs/fds/ guidelines/orthodontics-covid19.pdf. [Last accessed on 20 Aug 2020].

Citation: Sunegha Kundal, Tulika Shokeen, Anubhav Bansal. Dental Treatment during Covid-19: An Orthodontic Perspective. ARC Journal of Dental Science. 2020; 5(4):24-32. DOI: https://doi.org/10.20431/ 2456-0030.0504004.

Copyright: (c) 2020 Authors. This is an open-access article distributed under the terms of the Creative Commons Attribution License, which permits unrestricted use, distribution, and reproduction in any medium, provided the original author and source are credited. 